\title{
Comparative analysis methodologies formulation powers in the frequency domain
}

\author{
G.J. Schäffer ${ }^{1}$, S.L.Modesto ${ }^{1}$, T. S. Menezes ${ }^{1}$, Y. V. Tresso ${ }^{1}$, F. A. M. Moura ${ }^{1}$,M. V. B. Mendonça ${ }^{1}$, P. H. O. \\ Rezende $^{1}$ and M. R. M. Castillo ${ }^{1}$ \\ ${ }^{1}$ Universidade Federal do Triângulo Mineiro, Electrical Engineering Department, Uberaba- Minas Gerais, Brazil \\ gabrielaschaffer3094@hotmail.com, sophia.lealm@yahoo.com.br,thiagosouzamenezes@hotmail.com, \\ yan.uftm@hotmail.com,fabricio@eletrica.uftm.edu.br,marcusmvbm@gmail.com, paulohenrique16@gmail.com, \\ rociodelpilar_21@hotmail.com
}

\begin{abstract}
With the increasing use of non-linear loads in electrical power systems, it is necessary to study the harmonic distortion, which if not considered in the power calculations may result in measurement errors. Therefore, this study aims to present a comparative analysis between two power theories in the frequency domain, Budeanu theory and IEEE 1459 standard, before a case study, in the presence or absence of distortions of a system electrical test.
\end{abstract}

\section{Key words}

Electric power. Harmonic distortion. Imbalance. Quality electricity.

\section{Introduction}

In order to understand the fact that the power be greater apparent that the consumed active power and to mitigate this, apparent power, without changing the active power delivered to the loads was developed classical theory formulation electrical power in order to better understand and substantiate the transfer of energy in an electrical circuit. However, the whole theory applied to the quantification and power analysis in electrical networks, was implemented by a sinusoidal system, balanced and operating at the fundamental frequency. However, from the 60, Figure 1, there was a significant growth in the use of electronic loads, which have non-linear characteristics, ie, produce whole multiple components and not whole the fundamental, namely: harmonic and interharmonic.

In this context the study of the theory of electric power in the presence of harmonic distortion, shown vital for the analysis and understanding of the energy transfer circuit.

Several research and technical discussions have been developed in order to explain the power of phenomena in non-sinusoidal systems. However, these methods must be compatible and meet the classical theory of powers in sinusoidal regime.

In that order, more precisely in 1927, There was the first theories and formulations developed by Budeanu. Nevertheless, in 1932, Fryze published his theories and since there is no consensus on the best topology to be applied. Aiming to establish a standard to be adopted by the scientific community and international production, the document of the Institute of Electrical and Electronics Engineers - IEEE 1459 has been established as a basic premise the decomposition of the apparent power in fundamental and not fundamental, demonstrating the power which come from distortions harmonic current and voltage [1], [2].

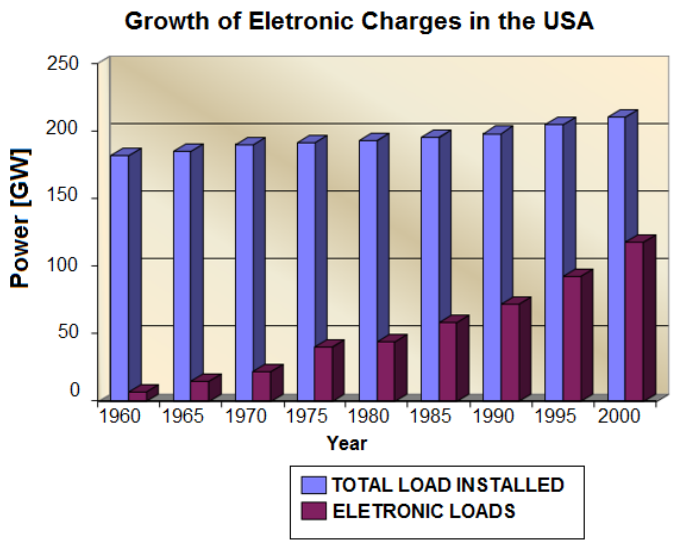

Fig. 1- Growth of electronic loads

Thus, this article presents a comparative analysis of the methodology employed by Budeanu and the IEEE 1459 for the quantification of powers in non-sinusoidal and unbalanced systems, in order to illustrate to the reader the main changes proposed new methodology. For purposes of further discussions, this article is structured as follows: the power of theories, which will be used are presented in section 2. In section 3 , it is shown the test system used in this work. In Section 4, the studies are presented by the electrical system employed with the comparisons between the theories of Budeanu and Emanuel (IEEE 1459). In Section 5 the main conclusions are built on the problems studied here. 


\section{Power formulation methodologies}

The main theories of powers under nonsinusoidal conditions, recognized worldwide were proposed in the time domain such as the theories of Czarnecki and Depenbrock, and also in the frequency domain, such as the theories of Budeanu and Emanuel, which is used currently the IEEE. Among these, the theories in the frequency domain will be highlighted, as comparative data between the work, which will be presented are based on proposals Budeanu and Emanuel which have a possibility of expression of power in an electrical system with harmonic distortion.

\subsection{Method Budeanu}

Constantin Budeanu theory was one of the first and is based on the use of Fourier series defined by Jean B. Fourier to describe the electrical circuit properties such as voltage and current signals. According to Fourier, any signal can be decomposed into a sum as follows:

$v(t)=V_{0}+\sum_{h=1}^{m} V_{h}^{t} \cos (h \omega t)+V_{h} \operatorname{sen}(h \omega t)$

Since $V_{o}$ the DC component of the signal and the $h$ index of the harmonic order, we have $V_{h}$ and $V_{h}^{\prime}$ how amplitudes of harmonic components and $h w$ the angular frequency of each harmonic order. However, since most of the components of an electrical system is represented by odd function and the continuous component being disregarded, $V_{h}^{\prime}$ and $V_{0}$ becomes equal to zero. So, in instantaneous value has to [3]:

$$
v(t)=\sqrt{2} \sum_{m=1}^{m} V_{m} \operatorname{sen}\left(m \omega t-\varphi_{v_{m}}\right)
$$

Where $V_{m}$ is the voltage amplitude and $\varphi_{v_{m}}$ the voltage phase angle. The analysis is made for the current analogously. Furthermore, Budeanu postulated that non-sinusoidal conditions, the apparent power can be fractionated into active power and active power does not, the latter being divided into Budeanu reactive power and distortion power which are represented by the following $Q_{B}$ e $D_{B}$, respectively.

$$
Q_{B}=\sum_{h=1}^{\infty} Q_{h}=\sum_{h=1}^{\infty} V_{h} I_{h} \operatorname{sen} \varphi_{h}
$$

$$
D_{B}=\sqrt{\sum_{\substack{n, m \\ n \neq m}}^{m}\left[V_{n}^{2} I_{m}^{2}+V_{m}^{2} I_{n}^{2}-2 V_{n} I_{n} V_{m} I_{m} \cos \left(\varphi_{m}-\varphi_{n}\right)\right]}
$$

Therefore, the equation governing the apparent power is given by [1]:

$$
S_{B}=\sqrt{P_{B}^{2}+Q_{B}^{2}+D_{B}^{2}}
$$

Regarding the power factor represented by Budeanu follows the two equations[2]:

$$
\begin{gathered}
f p_{B}=\frac{p_{B}}{S_{B}} \\
f p_{Q}=\frac{P_{B}}{\sqrt{P_{B}^{2}+Q_{B}^{2}}}
\end{gathered}
$$

However, the power formulation defined by Budeanu is very questionable. One major criticism was made by Czarneki which cites the lack of reactive power input to improve the power factor and the fact that the distortion power has no relation to the distortion of waveforms in a circuit [4]. With this, the update of the IEEE 1459 standard does not mention the concepts of Budeanu.

\section{2-IEEE Method 1459}

Alexander Emmanuel, president of the group of non-sinusoidal situations studies IEEE proposed a similar power decomposition of the Budeanu which is divided into active power, reactive and distortion. However, this decomposition differs in the way of obtaining the powers, which in this case consists in the separation of the fundamental component of the harmonic components of voltage and current as shown below.

$$
\begin{gathered}
V^{2}=V_{1}^{2}+\sum_{h \neq 1} V_{h}^{2}=V_{1}^{2}+V_{H}^{2} \\
I^{2}=I_{1}^{2}+\sum_{h \neq 1} l_{h}^{2}=I_{1}^{2}+I_{H}^{2}
\end{gathered}
$$

Where the index 1 represents the fundamental components and the index $\mathrm{h}$, the harmonics. It is noticed that Alexander makes a square sum of harmonic components of voltage and current, causing the apparent power from (9) and (10):

$$
\begin{aligned}
& S^{2}=V^{2} l^{2}=\left(V_{1}^{2}+V_{H}^{2}\right) *\left(l_{1}^{2}+l_{H}^{2}\right)=\left(V_{1} l_{1}\right)^{2}+ \\
& \left(V_{1} l_{H}\right)^{2}+\left(V_{H} l_{1}\right)^{2}+\left(V_{H} l_{H}\right)^{2}=S_{1}^{2}+D_{l}^{2}+D_{V}^{2}+S_{H}^{2}
\end{aligned}
$$




$$
\begin{gathered}
S_{H}=\left(V_{H} I_{H}\right)=S_{1} \frac{V_{H} l_{H}}{V_{1} I_{1}}=S_{1}\left(T H D_{V}\right)\left(T H D_{l}\right) \\
P_{H}=\sum_{h \neq 1} P_{h}=\sum_{h \neq 1} V_{h} I_{h} \cos \theta_{h}
\end{gathered}
$$

Where $\mathrm{S} 1$ is the apparent fundamental power, D1 the power of current distortion, Dv the power of voltage distortion, $\mathrm{SH}$ the harmonic apparent power and $\mathrm{PH}$ the harmonic active power which, according to the author, is an indication that reveals the harmonic pollution in charge. It should be remembered that the achievement of the fundamental powers is performed identically to the classic method, it is not necessary here to submit the same. Moreover, the author (Emanuel) relates the fundamental reactive power as needed to improve the power factor. Thus, it defined the apparent no fundamental power SN that according to Alexander, it would be a good estimate of the size of the harmonic compensator [2].

$$
S_{N}=\sqrt{D_{I}^{2}+D_{V}^{2}+S_{H}^{2}}
$$

The amount of power related to voltage and current distortion is given by the distortion equations described in (15) and (16).

$$
\begin{aligned}
& D_{V}=\left(V_{H} I_{1}\right)=I_{1} \sqrt{\sum_{n \neq 1} V_{h}^{2}} \\
& D_{I}=\left(V_{1} I_{H}\right)=V_{1} \sqrt{\sum_{\hbar \neq 1} I_{h}^{2}}
\end{aligned}
$$

Similar to performed with voltage, current and power, the power factor also separates the fundamental component, thus it has the real power factor and displacement power factor which are presented respectively by equations (17) and (18).

$$
\begin{gathered}
f p=\frac{F}{S} \\
f p_{1}=\frac{P_{1}}{S_{1}}
\end{gathered}
$$

Notably, the calculation of the power factor does not include directly the reactive component, only active power and apparent, unlike Budeanu. Thus, although there is a part that says controversial this formulation, which refers to the reactive power and distortion on their physical interpretations and definitions for the full power of distortion, this method was adopted by the IEEE Standard 1459 in 2010 and It is used in this work.

\section{Computational Modeling: IEEE 1459}

For the purpose to evaluate and validate the computational model developed in this article it was used in the electrical system shown in Figure 2. This system refers to a small industrial consumer loads presenting the constant impedance type, constant power and non-linear loads. The electrical arrangement resembles a real power system and, second, the author, this is represented by a three-phase voltage source in series with an equivalent impedance which represents the short circuit system level.

It has been dealing with consumer unit, this contains linear loads and a bank of capacitors for power factor correction. Moreover, to represent non-linear loads, there are sources of harmonic current. To develop the model, figure 2, we used the software ATPDraw, thus the data required for the implementation thereof were taken from reference [5].

In order to carry out a comparative analysis between the Budeanu methodology and the proposed IEEE 1459, a computer interface was developed in Matlab software, using as a resource to guide tool, oriented language software object. In this regard, considering the equations (9) to (18) as well as all formulations used the classic method of power calculation for key components held code development and its subsequent validation using as parameter reference [2]. After this stage, it was initiated the development of the graphical interface shown in Figure 3.

By observing the interface, it can see that the user must enter the data voltage, current and their proper angles in order to obtain the values expressed by the letters corresponding to the rule mentioned in the previous section, IEEE 1459. For the power calculations, who regard voltage amplitudes or current of each harmonic order, it was considered to the 25th harmonic order, to meet the module 8 of the Distribution Procedures - PRODIST, [6]. It is noteworthy that the data to be obtained are single-phase, so phase-neutral. 


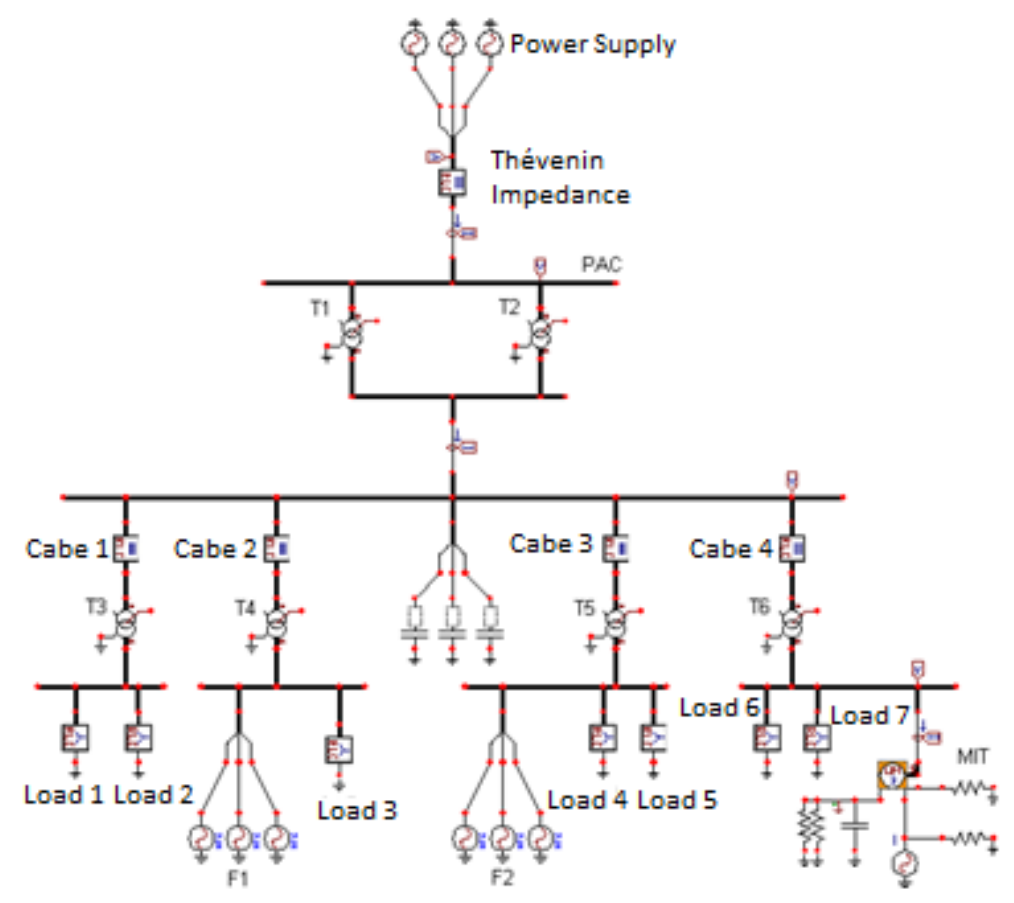

Fig.2- Electrical Test System.

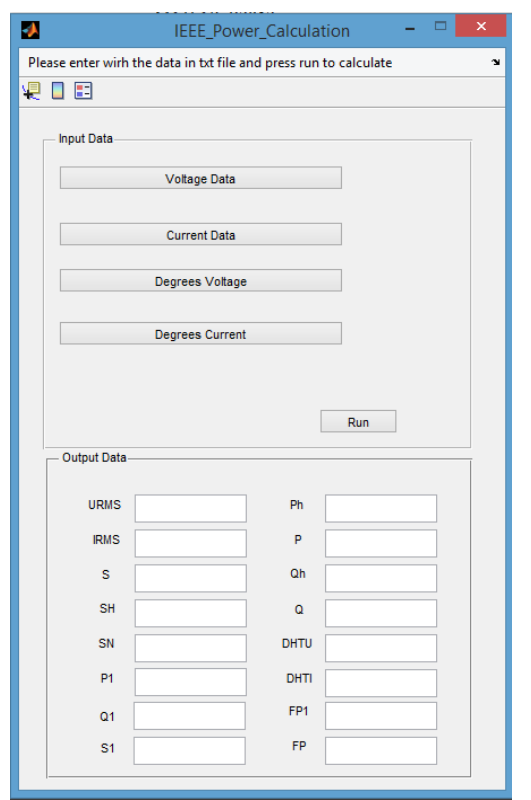

Fig. 3 Graphical Interface for Power Calculation.

In order to validate the developed program, we used the test system shown previously, Figure 2, and the data indicated in Table 5 in the next section, case studies. Thus, the values shown in the figure was obtained 4 . The values in the interface were compared to the values submitted by reference [2], which the author was used the same case study and the same equations presented for power calculation. Thus, the implementation of the code along with the graphical interface, in a way, accelerates the calculation power because this interface has been developed in order to obtain practical results, efficient and teaching.

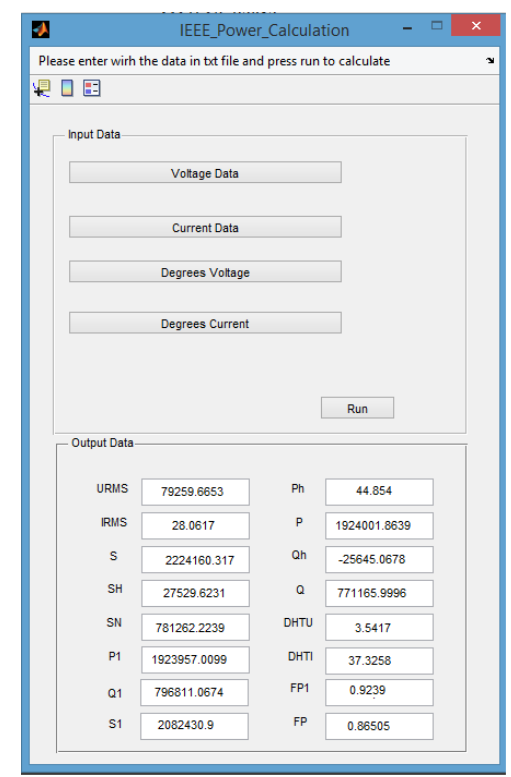

Fig.4-values obtained by Case II data.

\section{Case Study}

In this section the case studies will be presented with different operating conditions for electrical testing system. The analyzes for this study will be carried out with emphasis on the point of common coupling between a system supplier and an industrial consumer unit. The studies were oriented along the reference [2] for comparison purposes. After the presentation of this, the power will be applied methodologies described in section 2 with a critical analysis for each case. 


\subsection{Case I}

In this case, the supply voltage is purely sinusoidal and there are no nonlinear loads, i.e. without sources of current and voltage harmonics, but the presence saturation of the ferromagnetic core of the transformer generates small harmonic distortion current. Analyzing only phase A for all the cases, Table 1 shows the effective values of voltage, current and individual harmonic distortion of voltage and current which are calculated based on equations (19) and (20) respectively.

$$
\begin{aligned}
& D I T_{h} \%=\frac{V_{h}}{V_{1}} \cdot 100 \\
& D I I_{h} \%=\frac{I_{h}}{I_{1}} \cdot 100
\end{aligned}
$$

Table 1- Operating Conditions I

\begin{tabular}{c|c|c|c|c}
\multirow{2}{*}{$\begin{array}{c}\text { Harmonic } \\
\text { Ordem }\end{array}$} & \multicolumn{2}{|c|}{ Neutral-Phase Voltage } & \multicolumn{2}{c}{ Current } \\
\cline { 2 - 5 } & {$[\mathbf{V}]$} & DIT [\%] & {$[\mathbf{A}]$} & DII [\%] \\
\hline $1^{\mathbf{a}}$ & $79210\left\llcorner-1,017^{\circ}\right.$ & - & $26,27\left\llcorner-23,5^{\circ}\right.$ & - \\
\hline $5^{\mathbf{a}}$ & $54,54\left\llcorner 179,5^{\circ}\right.$ & 0,07 & $0,0564\left\llcorner 113,1^{\circ}\right.$ & 0,21 \\
\hline $7^{\mathbf{a}}$ & $43,8\left\llcorner-79,1^{\circ}\right.$ & 0,06 & $0,0174\left\llcorner 164^{\circ}\right.$ & 0,07 \\
\hline $11^{\mathbf{a}}$ & $20,15\left\llcorner-167,8^{\circ}\right.$ & 0,03 & $0,0207\left\llcorner 86,94^{\circ}\right.$ & 0,08 \\
\hline $13^{\mathbf{a}}$ & $19,47\left\llcorner-170,6^{\circ}\right.$ & 0,02 & $0,0096\left\llcorner 97,79^{\circ}\right.$ & 0,04
\end{tabular}

It should be noted that although the table is present only 5 components, all calculations are made to the 25th harmonic order.

In Table 2, the application of the first case is presented in all the equations (2) to (7), mentioned in section 2 as Budeanu method, with values of single-phase power. In Table 3, application in all the equations (9) is displayed (18) as Emanuel method.

Table 2- Budeanu method for Case I

\begin{tabular}{c|c|c|c|c|c}
$\boldsymbol{S}_{\boldsymbol{B}}$ & $\boldsymbol{P}_{\boldsymbol{B}}$ & $\boldsymbol{Q}_{\boldsymbol{B}}$ & $\boldsymbol{D}_{\boldsymbol{B}}$ & $\boldsymbol{f} \boldsymbol{p}_{\boldsymbol{B}}$ & $\boldsymbol{f} \boldsymbol{p}_{\boldsymbol{Q}}$ \\
\hline $2080.88 \mathrm{kVA}$ & $1922.711 \mathrm{~kW}$ & $795.741 \mathrm{kVAr}$ & $6.28 \mathrm{kVA}$ & 0.924 & 0.924
\end{tabular}

Noting the above tables, it can see the proximity of the values of power and power factor. Thus, it appears the validity and similarity of two theories for sinusoidal systems. Note also that the harmonic current distortion rate is much higher compared to voltage. Regarding the power Budeanu distortion, this has a high value, thus showing a lack of physical interpretation of it.

\begin{tabular}{|c|c|c|c|c|c|}
\hline \multicolumn{2}{|l|}{$s$} & \multicolumn{2}{|r|}{$P$} & \multicolumn{2}{|c|}{$P_{H}$} \\
\hline \multicolumn{2}{|c|}{$2080.88 \mathrm{kVA}$} & \multicolumn{2}{|c|}{$1922.711 \mathrm{~kW}$} & \multicolumn{2}{|c|}{$0.023 \mathrm{~kW}$} \\
\hline \multicolumn{2}{|l|}{$s_{1}$} & \multicolumn{2}{|r|}{$P_{1}$} & \multicolumn{2}{|c|}{$Q_{1}$} \\
\hline \multicolumn{2}{|c|}{$2080.8466 \mathrm{kVA}$} & \multicolumn{2}{|c|}{$1932.688 \mathrm{~kW}$} & \multicolumn{2}{|c|}{$795.735 \mathrm{kVAr}$} \\
\hline$S_{N}$ & $T D H_{I}$ & $\mathrm{TDH}_{U}$ & $S_{H}$ & $f p$ & $f p_{1}$ \\
\hline $11.759 \mathrm{kVA}$ & $0.44 \%$ & $0.36 \%$ & $0.032 \mathrm{kVA}$ & 0,924 & 0,924 \\
\hline
\end{tabular}

Table 3- Emanuel Method for Case I

\subsection{Case II}

In this case, inserted into non-linear loads in the system, i.e., current sources which have effective values according to Table 4 [5] and the data obtained are shown in Table 5 [2].
Table 4- Current Sources

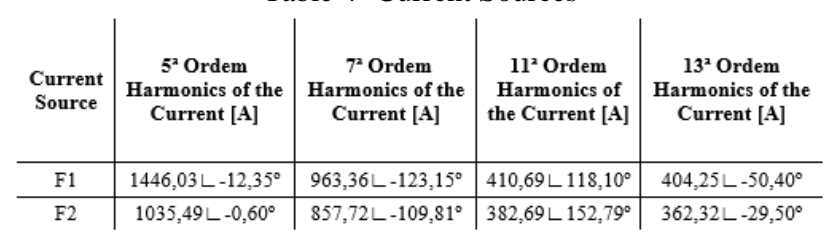

Table 5- Operating Conditions II

\begin{tabular}{c|c|c|c|c}
\multirow{2}{*}{$\begin{array}{c}\text { Harmonic } \\
\text { Ordem }\end{array}$} & \multicolumn{2}{|c|}{ Neutral-Phase Voltage } & \multicolumn{2}{c}{ Current } \\
\cline { 2 - 5 } & {$[\mathrm{V}]$} & DIT [\%] & {$[\mathbf{A}]$} & DII [\%] \\
\hline $1^{\mathrm{a}}$ & $79210\left\llcorner-1,023^{\circ}\right.$ & - & $26,29\left\llcorner-23,52^{\circ}\right.$ & - \\
\hline $5^{\mathrm{a}}$ & $1378\left\llcorner 133^{\circ}\right.$ & 1,74 & $7,071\left\llcorner-139,3^{\circ}\right.$ & 26,90 \\
\hline $7^{\mathrm{a}}$ & $1436\left\llcorner-100^{\circ}\right.$ & 1,81 & $5,326\left\llcorner-8,331^{\circ}\right.$ & 20,26 \\
\hline $11^{\mathrm{a}}$ & $1136\left\llcorner-87,68^{\circ}\right.$ & 1,43 & $2,693\left\llcorner 3,781^{\circ}\right.$ & 10,24 \\
\hline $13^{\mathrm{a}}$ & $1593\left\llcorner-23,62^{\circ}\right.$ & 2,01 & $3,528\left\llcorner 67,12^{\circ}\right.$ & 12,39
\end{tabular}

Thus, in Tables 6 and 7 shows the results for the Budeanu and Emanuel methods.

Table 6- Budeanu method for Case II

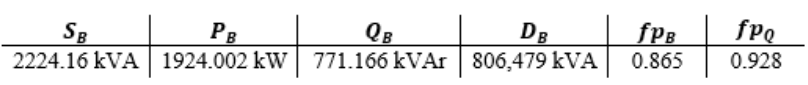

\begin{tabular}{|c|c|c|c|c|c|}
\hline \multicolumn{2}{|l|}{$s$} & \multicolumn{2}{|r|}{$P$} & \multicolumn{2}{|c|}{$P_{H}$} \\
\hline \multicolumn{2}{|c|}{$2224.16 \mathrm{kVA}$} & \multicolumn{2}{|c|}{$1924.002 \mathrm{~kW}$} & \multicolumn{2}{|c|}{$0.045 \mathrm{~kW}$} \\
\hline \multicolumn{2}{|l|}{$S_{1}$} & \multicolumn{2}{|r|}{$P_{1}$} & \multicolumn{2}{|c|}{$Q_{1}$} \\
\hline \multicolumn{2}{|c|}{$2082.431 \mathrm{kVA}$} & \multicolumn{2}{|c|}{$1923.957 \mathrm{~kW}$} & \multicolumn{2}{|c|}{$796.811 \mathrm{kVAr}$} \\
\hline$S_{N}$ & $T D H_{I}$ & $T D H_{U}$ & $S_{H}$ & $f p$ & $f p_{1}$ \\
\hline $781.263 \mathrm{kVA}$ & $3.54 \%$ & $37.33 \%$ & $27,5297 \mathrm{kVA}$ & 0,865 & 0,924 \\
\hline
\end{tabular}

Table 7- Emanuel method for Case II

Observing the reactive power data Budeanu, disability just to perceive when compared to the fundamental. It is noticed that this value is smaller, making it clear that there are negative harmonic reactive power. Moreover, Budeanu deficiency is perceived according to the calculation of the power factor $f p_{B}$, and uses the power of distortion $f P_{Q}$ and discards. By comparing the harmonic distortion of both voltage and current, it is clear that these values are much higher in the second case.

\subsection{Case III}

In this case, the supplement is unbalanced with values shown in Table 8 and the consumer has only linear loads. The data obtained from the system are presented in Table 9.

Table 8- Unbalance Power Suplly

\begin{tabular}{c|c} 
Power Supply & Phase-Phase Voltage (kV) \\
\hline Fase A & $140,76\left\llcorner 0^{\circ}\right.$ \\
\hline Fase B & $136,641\left\llcorner-121,002^{\circ}\right.$ \\
\hline Fase C & $136,641\left\llcorner 121,002^{\circ}\right.$
\end{tabular}

Table 9- Operating Conditions III

\begin{tabular}{c|c|c|c|c}
\multirow{2}{*}{$\begin{array}{c}\text { Harmonic } \\
\text { Ordem }\end{array}$} & \multicolumn{2}{|c|}{ Neutral-Phase Voltage } & \multicolumn{2}{c}{ Current } \\
\cline { 2 - 5 } & {$[\mathrm{V}]$} & DIT [\%] & {$[\mathbf{A}]$} & DII [\%] \\
\hline $1^{\mathbf{a}}$ & $80800\left\llcorner-1,011^{\circ}\right.$ & - & $26,86\left\llcorner-23,67^{\circ}\right.$ & - \\
\hline $5^{\mathbf{a}}$ & $56\left\llcorner 179,5^{\circ}\right.$ & 0,07 & $0,0548\left\llcorner 114,7^{\circ}\right.$ & 0,20 \\
\hline $7^{\mathbf{a}}$ & $44,92\left\llcorner 179^{\circ}\right.$ & 0,06 & $0,0177\left\llcorner 169,3^{\circ}\right.$ & 0,07 \\
\hline $11^{\mathbf{a}}$ & $20,36\left\llcorner-167^{\circ}\right.$ & 0,02 & $0,0224\left\llcorner 84,01^{\circ}\right.$ & 0,08 \\
\hline $13^{\mathrm{a}}$ & $19,51\left\llcorner-169,4^{\circ}\right.$ & 0,02 & $0,0106\left\llcorner 92,51^{\circ}\right.$ & 0,04
\end{tabular}


Thus, the tables 10 and 11 are presented the results for the Budeanu and Emanuel methods for this case.

Table 10- Budeanu method for Case III

\begin{tabular}{c|c|c|c|c|c}
$\boldsymbol{S}_{\boldsymbol{B}}$ & $\boldsymbol{P}_{\boldsymbol{B}}$ & $\boldsymbol{Q}_{\boldsymbol{B}}$ & $\boldsymbol{D}_{\boldsymbol{B}}$ & $\boldsymbol{f}_{\boldsymbol{B}}$ & $\boldsymbol{f}_{\boldsymbol{Q}}$ \\
\hline $2088.126 \mathrm{kVA}$ & $1930.069 \mathrm{~kW}$ & $796.886 \mathrm{kVAr}$ & $8.835 \mathrm{kVA}$ & 0.924 & 0.924
\end{tabular}

Table 11- Emanuel method for Case III

\begin{tabular}{|c|c|c|c|c|c|}
\hline \multicolumn{2}{|l|}{$S$} & \multicolumn{2}{|r|}{$P$} & \multicolumn{2}{|c|}{$P_{H}$} \\
\hline \multicolumn{2}{|c|}{$2088.126 \mathrm{kVA}$} & \multicolumn{2}{|c|}{$1930.069 \mathrm{~kW}$} & \multicolumn{2}{|c|}{$0.014 \mathrm{~kW}$} \\
\hline \multicolumn{2}{|l|}{$s_{1}$} & \multicolumn{2}{|r|}{$P_{1}$} & \multicolumn{2}{|c|}{$Q_{1}$} \\
\hline \multicolumn{2}{|c|}{$2088,103 \mathrm{kVA}$} & \multicolumn{2}{|c|}{$1930.055 \mathrm{~kW}$} & \multicolumn{2}{|c|}{$796.884 \mathrm{kVAr}$} \\
\hline$S_{N}$ & $\mathrm{TDH}_{I}$ & $\mathrm{TDH}_{U}$ & $S_{H}$ & $f p$ & $f p_{1}$ \\
\hline $9.739 \mathrm{kVA}$ & $0.44 \%$ & $0.36 \%$ & $0.022 \mathrm{kVA}$ & 0,924 & 0,924 \\
\hline
\end{tabular}

In the case of voltage unbalance, it can see changes in the values of power, but it did not alter the power factor when compared to the first case, since the load conditions were maintained and the analysis is done similarly to the case I.

\subsection{Case IV}

In this case, the balance is maintained and the consumer presents linear and nonlinear loads. The data obtained are shown in Table 12.

Table 12- Operational Condition IV

\begin{tabular}{c|c|c|c|c}
\multirow{2}{*}{$\begin{array}{c}\text { Harmonic } \\
\text { Ordem }\end{array}$} & \multicolumn{2}{|c|}{ Neutral-Phase Voltage } & \multicolumn{2}{c}{ Current } \\
\cline { 2 - 5 } & {$[\mathbf{V}]$} & DIT [\%] & {$[\mathbf{A}]$} & DII [\%] \\
\hline $1^{\mathrm{a}}$ & $80790\left\llcorner-1,023^{\circ}\right.$ & - & $26,86\left\llcorner-23,71^{\circ}\right.$ & - \\
\hline $5^{\mathrm{a}}$ & $1377\left\llcorner 133,1^{\circ}\right.$ & 1,70 & $7,061\left\llcorner-139,3^{\circ}\right.$ & 26,29 \\
\hline $7^{\mathrm{a}}$ & $1436\left\llcorner-99,97^{\circ}\right.$ & 1,78 & $5,322\left\llcorner-8,226^{\circ}\right.$ & 19,81 \\
\hline $11^{\mathrm{a}}$ & $1133\left\llcorner-87,78^{\circ}\right.$ & 1,40 & $2,683\left\llcorner 3,714^{\circ}\right.$ & 9,99 \\
\hline $13^{\mathrm{a}}$ & $1587\left\llcorner-23,71^{\circ}\right.$ & 1,96 & $3,247\left\llcorner 67,05^{\circ}\right.$ & 12,09
\end{tabular}

Thus, Tables 13 and 14 show the results for the methods already discussed. For non-sinusoidal regimes as presented in the case IV, where there is so much imbalance and harmonic current sources, the difference between conventional methods and studied in this work is even more worse. Comparing this case with Case II, it is observed that the value of the harmonic distortion have more interference than the voltage imbalance. Moreover, when changing the system power, the harmonic active power has been increased due to the influence of this change in circuit components. We notice also that the distortion values are higher when compared to the case III, since it entered non-linear loads.

Table 13- Budeanu method for Case IV

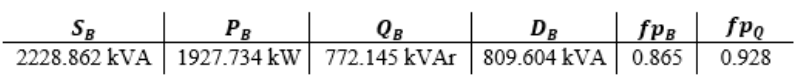

\begin{tabular}{|c|c|c|c|c|c|}
\hline \multicolumn{2}{|l|}{$S$} & \multicolumn{2}{|r|}{$P$} & \multicolumn{2}{|c|}{$P_{H}$} \\
\hline \multicolumn{2}{|c|}{$2228.862 \mathrm{kVA}$} & \multicolumn{2}{|c|}{$1927.734 \mathrm{~kW}$} & \multicolumn{2}{|c|}{$0.123 \mathrm{~kW}$} \\
\hline \multicolumn{2}{|l|}{$S_{1}$} & \multicolumn{2}{|r|}{$P_{1}$} & \multicolumn{2}{|c|}{$Q_{1}$} \\
\hline \multicolumn{2}{|c|}{$2086.184 \mathrm{kVA}$} & \multicolumn{2}{|c|}{$1927.611 \mathrm{~kW}$} & \multicolumn{2}{|c|}{$797.769 \mathrm{kVAr}$} \\
\hline$S_{N}$ & $T D H_{I}$ & $T D H_{U}$ & $S_{H}$ & $f p$ & $f p_{1}$ \\
\hline $784.527 \mathrm{kVA}$ & $3.47 \%$ & $36.48 \%$ & $27.529 \mathrm{kVA}$ & 0,865 & 0,924 \\
\hline
\end{tabular}

\section{Conclusion}

Thus, through the analyzes presented here, it is clear the need to define a method for non-sinusoidal situations, since the classical method of power calculation does not account for the influence of harmonic distortion and voltage imbalance, which may be a factor harmful when it comes to power measurement in an electrical system whose distortions are present. Therefore, this work presents a comparative study between two power theories of Budeanu and IEEE 1459 standard, used on a large scale today. However, it is evident this article disability of the first method with respect to reactive power distortion, which is, in the case of harmonic distortion, less than the fundamental reactive power, that is, there are big differences in reactive power calculations and distortion to the methods. However, referring to the values of active power is no similarity between the two methods. Furthermore, with regard to the imbalance it can be noted that both cases is not of a specific calculation for this. Thus, it is noted that there are flaws in all methods and then the choice of the appropriate method depends on the implementation.

\section{Acknowledgement}

The authors acknowledge the financial support from the Universidade Federal do Triângulo Mineiro - UFTM.

\section{References}

[1] LIMA, Ezequiel J. Reflexões sobre as teorias de potência elétrica em regime não senoidal. Dissertação de mestrado para obtenção do título de mestre em Engenharia Elétrica Universidade Federal de Uberlândia. Uberlândia, 2014.

[2] MODESTO, S. Avaliação Computacional de Métodos de Obtenção da Potência Elétrica para Tensões e Correntes Equilibradas e Desequilibradas com Distorções Harmônicas. Universidade Federal do Triângulo Mineiro. Uberaba, 2015.

[3] VIERA, Daniel. Comparação de Técnicas de Medição de Potência Reativa sob Condições Não-Senoidais com Ênfase na Transformada Wavelet. Dissertação de mestrado para obtenção do grau de mestre em Engenharia Elétrica - Faculdade de Tecnologia da Universidade de Brasília. Brasília, 2012.

[4] ] CZARNECKI, L. S. What is wrong with the Budeanu Concept of Reactive and Distortion Power and Why It Should be Abandoned. IEEE Transactions on Instrumentation and Measurement, 1987.

[5] SANTOS, Andréia Crico. Uma Contribuição ao Processo do Compartilhamento de Responsabilidade sobre as distorções Harmônicas via Chaveamento de Unidades Capacitivas. Dissertação de mestrado para obtenção do título de Mestre em Ciências - Faculdade de Engenharia Elétrica da Universidade Federal de Uberlândia. Uberlândia, 2015.

[6] PRODIST - Procedures for Electricity Distribution in the National Electric System, Module 8, Quality of Electricity, 2012. Available at: http://tinyurl.com/m3974dg . Accessed in Setember 30, 2016. \{In Portuguese

[7] IEE- The Institute of Electrical and Electronics Engineers, IEEE Tria-use Standard Definitions for the Measurements of Electric Power Quantities under Sinusoidal, Nonsinusoidal, Balances, or Unbalanced Conditions- Std 1459- 2000. New York, January 30, 2000.

[8] BALCI, M. E.;HOCAOGLU, M. H. Comparasion of Power Definitions for Reactive Power Compensation in Nonsinusoidal Conditions. 11th International Conference on Harmonics and Quality of Power, 2004. 